\title{
Power versus Affiliation in Political Ideology:
}

\section{Robust Linguistic Evidence for Distinct Motivation-Related Signatures}

\author{
Adam K. Fetterman ${ }^{1}$, Ryan L. Boyd ${ }^{2}$, and Michael D. Robinson ${ }^{3}$ \\ ${ }^{1}$ Knowledge Media Research Center \\ ${ }^{2}$ University of Texas at Austin \\ ${ }^{3}$ North Dakota State University
}

Word Count: 9,404

Note: Correspondence can be sent to Adam Fetterman, Knowledge Media Research Center, Schleichstrasse 6, 72076 Tübingen, Germany. Internet correspondence can be directed to A.Fetterman@iwm-kmrc.de (Phone: +49 7071 979-226; Fax: +49 7071 979-200). 


\begin{abstract}
Posited motivational differences between liberals and conservatives have historically been controversial. This motivational interface has recently been bridged, but the vast majority of studies have used self-reports of values or motivation. Instead, the present four studies investigated whether two classic social motive themes - power and affiliation - vary by political ideology in objective linguistic analysis terms. Study 1 found that posts to liberal chat rooms scored higher in standardized affiliation than power, whereas the reverse was true of posts to conservative chat rooms. Study 2 replicated this pattern in the context of materials posted to liberal versus conservative political news websites. Studies 3 and 4, finally, replicated a similar interactive (ideology by motive type) pattern in State of the State and State of the Union addresses. Differences in political ideology, these results suggest, are marked by, and likely reflective of, mindsets favoring affiliation (liberal) or power (conservative).
\end{abstract}

KEYWORDS: Political Ideology, Affiliation, Power, Language, Content Analysis 


\section{Power versus Affiliation in Political Ideology: Robust Linguistic Evidence for Distinct Motivation-Related Signatures}

Early theorists contended that political ideology has a basis in unconscious motivational dynamics that are characterological (e.g., Fromm, 1947). Such theories, though, were based on psychodynamic ideas that are now considered unproven at best and fallacious at worst, such as the idea of an anal character type (Crews, 2006; Kihlstrom, 1987). Inconsistent findings, the apparent malleability of some political attitudes, and dubious psychoanalytic inferences led several commentators to proclaim a moratorium on characterological depictions of political ideology (Converse, 1964; Shils, 1968).

In retrospect, this moratorium was premature (Jost, 2006). Irrespective of the potential malleability of political attitudes, they also possess an important degree of stability (Kerlinger, 1984). Further, several motivation-related frameworks have proven generative in recent years. Liberals value change to a greater extent, whereas conservatives value tradition (Piurko, Schwartz \&, Davidov, 2011). In addition, ideological conservatives score higher in the selfreported desire for certainty (Jost, Glaser, Kruglanski, \& Sulloway, 2003). Finally, it has been shown that openness to experience is systematically higher among liberals than conservatives (Carney, Jost, Gosling, \& Potter, 2008). In sum, recent evidence converges on the likelihood that motivational factors do vary by political ideology. As suggested by Jost (2006), the success of many of these recent studies is partly due to a focus on "core" ideological differences rather than those that might vary by topic or issue (e.g., the death penalty).

Perhaps somewhat surprisingly, this emerging literature has yet to focus, at least directly, on the classic (Atkinson, 1958; McClelland, 1987) motivational themes of power and affiliation. 
Affiliation is defined in terms of social connectedness, whereas power is defined in terms of dominance and influence (Trapnell \& Paulhus, 2012). It is intuitive to think that these social orientations should vary by political ideology. This point is first made. Subsequently, we follow McClelland (1987) in thinking that habitual social concerns are probably best assessed in implicit terms and present an objective assessment method for quantifying these themes in political texts. Relations between political ideology and motivation type - power versus affiliation - were then examined in four text-based studies, as outlined below.

\section{Political Ideology, Affiliation, and Power}

Lakoff (1996) presented a conceptual analysis of the distinct metaphors that seem to underlie liberal versus conservative viewpoints. Liberals appear motivated to think about society and the government as a warm, caring family. This metaphoric trope, if it is bound with a liberal ideology, possesses a marked similarity to characteristics of affiliation motivation, including its focus on warm, caring relationships (McClelland, 1987). On the other hand, conservatives appear motivated to think about society and the government in terms of authoritarian, disciplinary parents. This metaphoric trope, if true of a conservative ideology, possesses a marked similarity to power motivation and its emphasis on status and discipline (McClelland, 1987). It should be emphasized, though, that Lakoff's (1996) analysis was conceptual rather than empirical.

Yet, there are empirical findings that comport with Lakoff's (1996) analysis. Of particular note, Schwartz and colleagues have shown that values - defined in terms of ultimate goods to be pursued, by society as well as the self - vary by political ideology. Liberals favor "openness to change" (e.g., self-direction \& stimulation) values to a greater extent, whereas conservatives endorse "conservation" (e.g., conformity \& tradition) values more frequently (Barnea \& Schwartz, 1998; Caprara, Schwartz, Capanna, Vecchione, \& Barbaranelli, 2006). 
Openness to change values do not intuitively map onto affiliation concerns, but conservation values do intuitively map onto power concerns - i.e., concerns about status, violations to status, and preservation of status quo power relations (Caprara et al., 2006).

Another line of research is relevant. Building on earlier psychodynamic frameworks, Altemeyer (1981) showed that political conservatives more greatly endorsed items suggestive of a motivation to preserve status quo power relations, in this case termed Right Wing Authoritarianism. Subsequently, similar differences by political ideology were shown on a measure termed Social Dominance Orientation (Pratto, Sidanius, Stallworth, \& Malle, 1994). Incorporating such lines of evidence, system justification theory proposes that ideological conservatives are motivated to view power inequalities as justified, even when they reflect poorly on the self's status (Thorisdottir, Jost, \& Kay, 2009). Despite their nuances, we suggest that all such frameworks again converge on the idea that political conservatives appear to be power-oriented, though this suggestion would benefit from additional evidence.

Conversely, many of these same sources of data suggest greater affiliation among liberals. Liberals endorse greater equality, consistent with an ethic of caring (Sidanius \& Pratto, 1999). Similarly, they define what is moral and good more in terms of inclusiveness and helpfulness toward others (Graham, Haidt, \& Nosek, 2009), consistent with an affiliation orientation (Trapnell \& Paulhus, 2012). Relatedly, liberals are more favorable toward social issues and policies that seek to benefit others such as social welfare programs and affirmative action (Kerlinger, 1984). In sum, it appears consistent with the existing literature to suggest that affiliation may be more characteristic of a liberal political stance, whereas power may be more characteristic of a conservative political stance. We sought to provide support for this 
nonetheless novel idea in a textual-linguistic analysis of affiliation and power words in political communications, which were thought to systematically vary by political ideology.

\section{Computerized Scoring of Affiliation and Power}

McClelland (1987) views power and affiliation as implicit tendencies. A high affiliation person should, for example, somewhat naturally use more affiliation imagery when writing or speaking (Winter, 2003). Such tendencies are typically assessed in the Thematic Apperception Test (TAT), in which individuals write stories in response to pictures and the stories are coded for themes reflecting affiliation and power (Winter, John, Stewart, Klohnen, \& Duncan, 1998). This literature has shown that self-reports of affiliation or power rarely correlate with TAT-based assessments, yet TAT-based assessments seem to outperform self-reports in predicting spontaneous behaviors and long-term outcomes (McClelland, Koester, \& Weinberger, 1989).

Scoring TAT protocols, though, involves some subjective decision rules and TAT coding is difficult to master, perhaps accounting for why there are preciously few contemporary motivation researchers using TAT assessment methods in their research protocols. Moreover, there are known difficulties involving this method of assessment such as its great sensitivity to picture content, potentially low reliabilities, inter-coder agreement that is less than perfect, and order effects across successive stories (McClelland, 1987; Schultheiss, 2008). Although many of these difficulties can be overcome, it may also be useful to develop other scoring schemes that are not reliant on human coders (Schultheiss, 2013). A major contribution of the present investigation was that we could build on previous work in doing so.

In the 1950s, Philip Stone and his Harvard colleagues began a multiple-decades effort to create a comprehensive system for the analysis of written and spoken texts (Stone, 1997). Part of this effort involved the creation and revision of dictionaries covering key constructs in social- 
personality psychology and these dictionaries were expertly developed through a combination of theory, word menu (e.g., thesaurus) resources, expert ratings, and empirical evidence (Stone, Dunphy, Smith, \& Ogilvie, 1966). For example, dictionaries became larger and more inclusive over time, resulting in more reliable systems (Kelly \& Stone, 1975; Stone et al., 1966).

Over the years, Stone and his PhD students consulted with David McClelland, also a professor at Harvard, to develop computerized dictionaries for his "Big 3" motives of achievement, affiliation, and power. As reported in Stone et al. (1966) and Smith (1968), Litwin (1965) first developed a computerized dictionary for achievement, scoring for words such as "brilliant" and "original". Computer-assigned scores for a set of TATs converged strongly with expert hand scoring of the same protocols, with percent agreement figures of $70 \%$ to $97 \%$ (Smith, 1968). These figures are impressive in part because even well trained TAT coders rarely agree with each other above 90\% (Atkinson, 1958). Moreover, Litwin (1965) found that computer-assigned scores predicted behavioral outcomes in a manner consistent with achievement motivation theory (McClelland, 1961).

Smith (1968), the third author of Stone et al. (1966), then developed computerized systems for power and affiliation. The dictionaries were closely modeled on the implicit motivation literature, as they were designed to track the same themes that one looks for when coding TATs by hand (Atkinson, 1958; McClelland, 1987). Through an iterative process, and presumably in consultation with McClelland, Smith (1968) obtained good agreement with handscored TATs, with percent agreement figures as high as $96 \%$ for affiliation and $95 \%$ for power. Although Smith (1968) did not report validity evidence for his dictionaries, evidence of this type is reported by Hogenraad $(2003 ; 2005)$, who further developed the Harvard motive dictionaries and applied them to literary and political texts. Among other findings, Hogenraad (2005) showed 
that leader (e.g., George W. Bush) speeches contained a greater percentage of power to affiliation words as invasion (e.g., of Iraq) became more imminent. Because these findings are closely aligned with implicit motivation theory (McClelland, 1975) and with TAT-based analyses (e.g., Winter, 1993), Hogenraad (2005) concluded that there is good evidence for the utility of computer-based systems for assigning power and affiliation to individual texts.

Stone's (1997) goal was to develop a general platform for text-based studies; as a consequence, his publications tended to focus on general problems rather than specific dictionaries (e.g., Kelly \& Stone, 1975). Nonetheless, it is clear that Stone and his students consulted with McClelland to develop the Harvard IV motivation dictionaries (Stone et al., 1966), which were also upgraded and expanded subsequent to Litwin (1965) and Smith (1968). Schultheiss (2013) should also be cited here, as Schultheiss (2013) reports additional validity evidence for scoring implicit motivation by computer. In these studies, weighted combinations of word frequencies correlated with expert TAT scores, predicted emotional responses to goal progress, and responded to inductions intended to arousal power or affiliation motivation. On the basis of these results, Schultheiss (2013) encourages investigations of the present type, as we will use word dictionaries directly targeting the power and affiliation constructs.

Stone (1997), though, developed computerized algorithms that were too complex (Mehl, 2006). Accordingly, it is useful to take the Harvard IV dictionaries and add them to the Linguistic Inquiry and Word Count (LIWC) program (Pennebaker, Chung, Ireland, Gonzales, \& Booth, 2007), whose operations are more transparent (Tausczik \& Pennebaker, 2010). Work with the LIWC has concluded that individual differences in word usage are both reliable and valid (Pennebaker, Mehl, \& Niederhoffer, 2003). For example, word usage frequencies are stable over time (Pennebaker \& King, 1999), vary by group membership (e.g., men versus women: 
Newman, Groom, Handelman, \& Pennebaker, 2008), and predict important outcomes such as mental and physical health (Tausczik \& Pennebaker, 2010). The present studies build on this research to determine whether word usage also varies by political ideology.

Before concluding here, it is useful to make one methodological point. The Harvard IV power and affiliation dictionaries share a theoretical focus, but were developed somewhat independently (Stone, 1997; Stone et al., 1966). What this means in part is that there was no artificial effort to ensure that the dictionaries had the same number of words or were the same in their normative word frequencies (Kelly \& Stone, 1975). Nonetheless, the power versus affiliation comparison is a highly meaningful one, both generally (Fetterman, Robinson, \& Ode, 2015; McClelland, 1975) and in the present political context (Hogenraad, 2005; Winter, 1993). Accordingly, we followed precedent in standardizing these frequencies prior to comparing them (Martindale, 1990; Newman, Pennebaker, Berry, \& Richards, 2003; Slatcher, Chung, Pennebaker, \& Stone, 2007; Winter, 2003). The interactions that we report would emerge regardless, but the within-text comparisons require standardization to be informative.

\section{Overview of Studies}

The central hypothesis was that political ideology would interact with motive theme to predict word usage. In particular, each political ideology should have its own standardized motivational signature, either more affiliation- than power-oriented (liberal) or more power- than affiliation-oriented (conservative). We sought to examine this interactive hypothesis somewhat extensively. Study 1 harvested material posted to liberal and conservative chat rooms, a sampling design intended to capture political discourse among laypersons. Study 2 sampled posts to popular political news websites known to have an ideological slant, a sampling design intended to capture political discourse among powerful media sources. Study 3 analyzed State of the State 
addresses among elected Democratic versus Republican governors, thereby ensuring that prior interactive patterns generalize to elected politicians. Finally, Study 4 examined word frequencies in State of the Union addresses. We expected similar interactive patterns across the studies. For different reasons for each study, but also for the sake of comparability across studies, the focus was on political texts rather than particular individuals, as further discussed below.

\section{Study 1: Liberal versus Conservative Chat Room Texts}

Study 1 sought to examine discourse among politically involved laypersons. We could do this by sampling material posted to Internet Relay Chat (IRC) websites - i.e., "chat rooms" known to favor a particular ideological slant, either liberal or conservative. The advantage of sampling this source of texts is threefold. First, contributors are necessarily involved politically in that they choose to spend some of their free time sharing political opinions with others. Second, contributors to chat rooms are likely quite a bit more diverse in age, ethnicity, and state of residence than is true of undergraduate populations (Gosling, Sandy, John, \& Potter, 2010). Third, there is spontaneity to chat room discourse, a quality deemed informative to both the text analysis (Pennebaker et al., 2003) and social motive (McClelland, 1987) literatures.

\section{Method}

\section{Selection of Chat Rooms}

In selecting chat rooms, we used the searchirc.com Internet resource, which compiles traffic rates for IRCs of multiple types, politics included. This website was visited in November of 2010. By entering the terms "liberal" and "Democrat", we converged on the two most frequented liberal IRCs and by entering the terms "conservative" and "Republican", we converged on the two most frequented conservative IRCs. Texts were sampled from these four IRCs, which are in the public domain. 
Power versus Affiliation 11

\section{Text Samples}

We collected texts posted to the chat rooms for 8 consecutive 24-hour days, from November 11, 2010 to November 19, 2010. Posted texts are typically very short. Accordingly, it was necessary to sample time periods rather than particular comments. A visual inspection of these records indicated that 3-hour blocks might be ideal in balancing words per sample with number of samples. We therefore subdivided each 24-hour day into 8 time periods (e.g., 9 a.m. to 12 p.m., 12 p.m. to 3 p.m., etc.). Theoretically, this would result in 64 text samples per chat room, but one of the conservative IRCs exhibited low traffic rates in the early a.m., resulting in 53 samples for this specific website. There were therefore 245 total samples, 128 from the liberal chat rooms and 117 from the conservative chat rooms. In preparing texts for linguistic analysis, we deleted user names, channel codes, and system messages. On average, there were 3337 words per text sample, a healthy number of words for linguistic analyses (Pennebaker et al., 2003).

Quantifying the Frequency of Affiliation versus Power Words

Stone and colleagues developed their Harvard word dictionaries over many years, using a combination of theory, group brainstorming, word menu resources, expert ratings, and empirical results, in that order (Stone et al., 1966). This process is practically identical to that used to develop the LIWC dictionaries (Pennebaker et al., 2007), except that Stone's dictionaries were somewhat continuously revised over the period of 20 years (Kelly \& Stone, 1975) and graduate student theses were often involved (e.g., Litwin, 1965). Smith's (1968) power and affiliation dictionaries were modeled on the implicit motivation literature (Atkinson, 1958; McClelland, 1961), in consultation with McClelland, and they converged highly with expert TAT scoring (Smith, 1968). Subsequently, these dictionaries were expanded to take their final form in the 
Harvard IV dictionaries, which have been validated in a number of ways, though this validation process is only generally described in primary texts (Kelly \& Stone, 1975; Stone et al., 1966). As described by Smith (1968) and on the General Inquirer website, power words are those suggestive of power relationships, status, or influence attempts, whereas affiliation words are those suggestive of relationship closeness, group membership, or accommodation to the needs and wishes of others. These definitions, and thus the composition of the word lists, almost perfectly overlap with the implicit motivation literature (McClelland, 1961) because in fact the implicit motivation literature was the basis for the dictionaries (Stone et al., 1966). The Harvard IV versions code for 624 power words (e.g., "boss", “coerce”, "dominate”, "hero", "strong”, \& "victory") and 474 affiliation words (e.g., "care", "help", "intimate”, "kind”, "neighbor”, \& "volunteer"). Thus, the dictionaries are extensive, which is desirable (Mehl, 2006).

As a brief check on the dictionaries, we asked 4 judges to rate $(1=$ not at all; $7=$ extremely) all of the words according to two questions: "To what extent does the word relate to, or imply, POWER?” and "To what extent...AFFILIATION?" These ratings converged with each other, as reflected in alphas of .88 (power) and .90 (affiliation) across judges, with word as unit of analysis. Judges' ratings for a word were therefore averaged. Subsequently, we performed a 2 (Harvard IV category: power versus affiliation) by 2 (power rating versus affiliation rating) mixed-model ANOVA, again with word as unit of analysis. There was a sizeable interaction, $F$ $(1,1095)=961.52, p<.001, \eta_{\mathrm{p}}^{2}=.47(95 \% \mathrm{CI}: .428-.504)$, such that affiliation ratings were higher for affiliation $(M=3.95)$ than power $(M=1.83)$ words, $F(1,1095)=762.96, p<.001$, $\eta_{\mathrm{p}}{ }^{2}=.41(95 \% \mathrm{CI}: .369-.449)$, and power ratings were higher for power $(M=4.47)$ than affiliation $(M=2.45)$ words, $F(1,1095)=718.88, p<.001, \eta_{\mathrm{p}}{ }^{2}=.40(95 \%$ CI: $.355-.435)$. Thus, the power and affiliation dictionaries are sound. 
The General Inquirer scoring system is too complex, however (Mehl, 2006; Pennebaker et al., 2003). We therefore imported the Harvard IV power and affiliation dictionaries into the more commonly used LIWC program, which quantifies the percentage of text words, relative to total words, matching a particular dictionary (Pennebaker et al., 2007). We then ran the Study 1 chat room texts through this platform. Given that the power dictionary contained more words than the affiliation dictionary, it was not surprising that the normative frequency for the power category $(M=3.61 \% ; S D=1.57 \%$; skew $=2.88)$ was higher than the normative frequency for the affiliation category $(M=3.09 \% ; S D=1.35 \%$; skew $=3.30), F(1,243)=6.08, \mathrm{p}<.01$. Thus, in the absence of standardization, everyone - both liberals and conservatives - might seem to favor power over affiliation. This would be an artifact, however, of the power dictionary containing more words (Newman et al., 2003; Stone et al., 1966). Because we sought to compare the use of power versus affiliation words in a within-text, repeated-measures fashion, we zscored the two word categories such that each had a mean of 0 and a standard deviation of 1. Doing so corrects for the fact that the power dictionary includes more words and it also corrects for unequal variances (Martindale, 1990). ${ }^{1}$

\section{Results}

We hypothesized that the motive themes would significantly vary by the political ideology of chat room websites. To investigate this hypothesis, we conducted a mixed-model ANOVA. The between-text factor was Political Ideology (liberal versus conservative) and the within-text factor was Motive Type (affiliation versus power). The dependent measure was zscored word frequencies. In this analysis, there was a main effect for Political Ideology, $F$ (1, 243) $=5.42, p=.02, \eta_{\mathrm{p}}{ }^{2}=.02$, such that a higher frequency of coded words occurred in the 
conservative $(M=.136)$ relative to liberal $(M=-.124)$ texts. We discuss this result below. Given the standardization process, there was no main effect for Motive Type, $F<1$.

Of more importance, the hypothesized Political Ideology by Motive Type interaction was significant, $F(1,243)=11.10, p=.001, \eta_{\mathrm{p}}{ }^{2}=.04(95 \% \mathrm{CI}: .007-.103)$. As shown in Figure 1, comments made in liberal chat rooms more frequently used affiliation than power words, poststandardization, whereas comments made in conservative chat rooms more frequently used power than affiliation words. Follow-up repeated-measures ANOVAs sought to reinforce this interpretation of the results. Restricting the analysis to liberal chat rooms, the main effect for Motive Type was significant, $F(1,127)=14.57, p<.001, \eta_{\mathrm{p}}{ }^{2}=.10(95 \% \mathrm{CI}: .024-.208)$, and a marginally significant reversal was found for conservative chat rooms, $F(1,116)=3.42, p=.07$, $\eta_{\mathrm{p}}{ }^{2}=.03(95 \%$ CI: .000 - .110). What we particularly emphasize is the crossover nature of the latter patterns. ${ }^{2}$

\section{Discussion}

Deficit conditions often result in higher levels of motivational imagery (Atkinson, 1958; McClelland, 1987). The main effect for political ideology observed in Study 1 likely reflects such factors in that we obtained chat room materials during a time when Barack Obama was President of the United States and, in this context, conservatives were disenfranchised from the executive office. If so, we might observe a similar main effect in Study 2, which also sampled texts during the Obama administration, but not Studies 3 and 4, which analyzed the texts of State of the State and State of the Union addresses among elected leaders.

Ideology main effects, it should be stated, render it problematic to examine each motive theme separately in that such comparisons would confound motive-specific processes with main effects for ideology. Concretely, for example, they would suggest that there were ideology 
differences for power but not affiliation in Study 1 (see Figure 1), but affiliation but not power in Study 3 (see Figure 3). Confounding main effects are removed when one instead examines the relative use of power versus affiliation words within a given text or given ideology, following similar comparisons in the implicit motivation literature (Hogenraad, 2005; McClelland, 1975; Winter, 1987). At this level of analysis, the Study 1 results were clear: Posts to liberal chat rooms more frequently used affiliation than power words, post-standardization, whereas a reversed pattern was found among posts to conservative chat rooms. The strength of the Study 1 source of data was its focus on laypersons writing in a spontaneous manner in their communications with others. On the other hand, we could not text-analyze particular comments because they were typically very short. In addition, it would be useful to replicate the Study 1 interactive pattern with a very different source of textual data, which we sought to do in Study 2.

Study 2: Posts to Liberal versus Conservative Political News Websites Popular media is increasingly polarized along the liberal-conservative dimension. Whether related to TV (e.g., Fox versus MSNBC) or Internet (e.g., Huffington versus Drudge Report) news sources, the American populace can and often does exhibit a great deal of selectivity in choosing media sources consistent with their political leanings (Barker, 2002). Many (though not all) Internet news sources have a known ideological slant, even potentially in realms that are not ostensibly about politics (e.g., religion, entertainment, \& sports). Internet news sources, in turn, are viewed as powerful influences on political opinions and voting patterns (Jost, 2006). For such reasons, Study 2 content-analyzed texts posted to popular political news websites. We again hypothesized a political ideology by motive type interaction.

Method 
Ezbima.com tracks Internet traffic rates for the top 25 political news websites in terms of estimated unique visitors (EUV) per month. We obtained this list on June 9, 2010 and used it to select political news websites for text-sampling purposes. For the sake of generalizability, we sought to choose the 3 most frequented websites known to have a liberal ideological slant versus the 3 most frequented websites known to have a conservative slant. This led to the selection of Huffington Post $(\mathrm{EUV}=28,000,000)$, Salon $(\mathrm{EUV}=4,300,000)$, and Talking Points Memo $(\mathrm{EUV}=1,350,000)$ as the liberal news websites and Drudge Report $(\mathrm{EUV}=14,000,000)$, Politico $(\mathrm{EUV}=5,000,000)$ and Newsmax $(\mathrm{EUV}=4,200,000)$ as the conservative ones.

\section{Text Samples}

Archives were noticeably better for the previous 18 months than prior to this time period. Accordingly, texts were selected from within a January 1, 2009 to June 30, 2010 window, as data were harvested at the end of June, 2010. This is a large time window and the relevant websites posted a great number of texts, even on particular days. We therefore used random selection procedures, which are powerful and unbiased in representing a larger number of entities. In particular, we decided to randomly select 100 entries from each website and used the following procedures in doing so. Prior to collecting each text sample, a random date was chosen within the designated time window. All posts to the particular website on the given day - including seemingly non-political posts related to entertainment or sports - were numbered and then one was randomly chosen, subsequent to which its title and graphics were removed. Then another date was randomly chosen, etc. This process resulted in 300 text files per ideological slant. On average, each post consisted of 578 words. 
Procedures for quantifying the frequency of affiliation versus power words were identical to Study 1. That is, we imported the affiliation and power word dictionaries of the Harvard IV version of the General Inquirer (Stone, 1997) into the LIWC software program (Pennebaker et al., 2007) and then computed word frequencies for each motivation category. Power words were more frequent $(M=4.93 \% ; S D=2.62 \%$; skew $=1.07)$ than affiliation words $(M=3.31 \% ; S D=$ 2.06; skew $=2.36), F(1,598)=174.89, p<.01$, but this main effect is almost certainly due to the imbalance in the number of power and affiliation words scored (Kelly \& Stone, 1975; Stone et al., 1966). We therefore z-scored the categories so they could be meaningfully compared (Martindale, 1990; Newman et al., 2003).

\section{Results}

A mixed-model ANOVA parallel to Study 1 was conducted. The between-text factor was Political Ideology (liberal versus conservative) and the within-text factor was Motive Type (affiliation versus power). As in Study 1, there was a main effect for Political Ideology, F (1, $598)=12.61, p<.001, \eta_{\mathrm{p}}{ }^{2}=.02$. Posts to conservative websites included a higher frequency of motive words $(M=.107)$ than posts to liberal websites $(M=-.107)$. We attribute this main effect to the fact that President Obama was in office during the time of data collection (see the Study 1 Discussion section). On the other hand, there was no main effect for Motive Type, $F<1$, nor should there be given the standardization process.

Of most importance, and consistent with Study 1, there was a good-sized Political Ideology by Motive Type interaction, $F(1,598)=57.64, p<.001, \eta_{\mathrm{p}}{ }^{2}=.09(95 \%$ CI: $.050-$ .134) (see Figure 2). After standardization, affiliation words were more frequent than power words in liberal posts, $F(1,299)=20.59, p<.001, \eta_{\mathrm{p}}{ }^{2}=.06(95 \%$ CI: .021 - .124), whereas power words were more frequent than affiliation words in conservative posts, $F(1,299)=48.03$, 
$p<.001, \eta_{\mathrm{p}}{ }^{2}=.14(95 \% \mathrm{CI}: .074-.211)$. Thus, and despite the fact that the posts often concerned seemingly non-political events (e.g., entertainment happenings), each political ideology was characterized by a distinct motivational signature.

Recall that there were 3 liberal websites and 3 conservative websites. Additional support for the reliability of the motivational signatures could thus be obtained by showing that they were general across websites of a given ideology. To examine this issue, we conducted 3 (Website) by 2 (Motive Type) mixed-model ANOVAs, one for each ideology. There was no interaction for posts to the liberal websites, $F(2,198)=2.09, p=.13, \eta_{\mathrm{p}}{ }^{2}=.01$, or conservative websites, $F<1$. Thus, the liberal signature was consistent across liberal websites and the conservative signature was consistent across conservative websites.

\section{Discussion}

Political news websites are heavily trafficked and are thought to both reflect and shape the psychological mindsets of liberals versus conservatives (Jost, 2006). Despite the fact that such posts are heterogeneous in content, we found an ideology by motive type interaction in Study 2 that was very consistent with the interactive pattern observed in Study 1. Namely, it appears that liberal thinking is more affiliation- than power-oriented and conservative thinking is more power- than affiliation-oriented.

Although it quite reasonable to suggest that the posts analyzed in Studies 1 and 2 varied by the posters' political ideologies, we cannot know this for certain. Thus, it would be valuable to extend the results of Studies 1-2 by analyzing the words used by elected officials known to harbor liberal versus conservative ideologies. In Study 3, we focused on State of the State addresses among elected governors.

Study 3: State of the State Addresses 
The two-party system in American politics is largely defined in terms of political ideology, with Democratic politicians generally espousing more liberal social and economic policies and Republican politicians generally espousing more conservative social and economic policies (Maisel, 2007). Therefore, and given Study 3's focus on elected politicians, we contrasted the speeches of Democratic versus Republican governors, which have been transcribed and archived since 2002. In this context also, we predicted an ideology by motive type interaction whose pattern should be parallel to that observed in prior studies.

Method

\section{State of the State Addresses}

Stateline.org has transcribed State of the State addresses for all 50 states since the year 2002 and this Internet resource was used in Study 3. Four of these governors were independent in political affiliation and their addresses were accordingly excluded. Additionally, there are 5 states (e.g., North Dakota, Texas) in which governors give State of the State addresses once every two years rather than every year. Finally, there were 26 State of the State addresses that were missing. The remaining addresses, from 2002 to 2011, were included.

Our general focus was on political texts rather than individuals and this was true in Study 3 as well. That is, we treated each State of the State address as an independent entity. Doing so makes sense. Pragmatically, this analysis strategy is more powerful than averaging texts by governor. Further, each State of the State address is almost certainly the product of a different team of writers, as it reflects the state's status at the time of the speech, with a heavy emphasis on the prior year's achievements. Political speeches, that is, can be thought of as snapshots of an administration at a moment in time (Hogenraad, 2005; Winter, 1993). There were 219 State of 
the State speeches by Democratic governors and 222 speeches by Republican governors (total $N$ = 441). The average number of words per speech was 4293 .

\section{Quantifying the Frequency of Affiliation versus Power Words}

Procedures identical to the prior studies were used to quantify the frequency of affiliation versus power words, here in the context of State of the State addresses. Power words $(M=$ $5.59 \% ; S D=0.68 \%$; skew $=0.23)$ were more common than affiliation words $(M=5.52 \% ; S D=$ $0.86 \%$; skew $=0.07)$, though the comparison was not significant in Study $3, F(1,440)=2.32, p$ $>$.10. Nonetheless, the categories were z-scored to place them on a common scale (Newman et al., 2003), also rendering comparisons to the other studies more parallel.

\section{Results}

Standardized word frequencies were analyzed in a Political Ideology (here defined by the governor being a Democrat or Republican) by Motive Type mixed-model ANOVA. There was a main effect for Political Ideology, $F(1,440)=5.52, p=.02, \eta_{\mathrm{p}}{ }^{2}=.01$, but it was opposite in direction to those observed in Studies 1 and 2. Specifically, the State of the State addresses of Democratic governors contained more motive words $(M=.086)$ than the State of the State addresses of Republican governors $(M=-.084)$. Although not of central interest, such results suggest that the main effects of Studies 1 and 2 were likely due to conservatives writing during a Democratic presidential administration. There was no main effect for Motive Type, $F<1$.

Of more importance, the Political Ideology by Motive Type interaction was significant, $F$ $(1,440)=5.82, p=.02, \eta_{\mathrm{p}}{ }^{2}=.01(95 \% \mathrm{CI}: .0003-.042)$. Means for this interaction are reported in Figure 3 and they are consistent with the interactive patterns observed in Studies 1 and 2. Affiliation relative to power words were more frequent in Democratic State of the State addresses, though this comparison was marginally significant, $F(1,218)=3.17, p=.08, \eta_{\mathrm{p}}{ }^{2}=$ 
.01 (95\% CI: .000 - .060). By contrast, power relative to affiliation words were more frequent in Republican State of the State addresses, though this comparison was not significant, $F(1,222)=$ $2.68, p=.10, \eta_{\mathrm{p}}{ }^{2}=.01(95 \% \mathrm{CI}: .000-.055)$. Regardless, we emphasize the crossover nature of the interactive pattern.

\section{Discussion}

The database for Study 1 consisted of laypersons and the database for Study 2 consisted of posts to liberal versus conservative political news websites. It therefore remained uncertain whether the interactive results observed in the first two studies generalize to elected politicians with known (liberal versus conservative) party affiliations. Study 3 filled this gap in our knowledge. A political ideology by motive type interaction parallel to Studies 1 and 2 was found when analyzing the texts of State of the State addresses among elected governors. Follow-up comparisons for the interaction were not as strong as those observed in Studies 1 and 2, though, which we attribute to the greater centrism of elected governors than elected presidents (Maisel, 2007). If so, a larger effect size may be found in State of the Union addresses.

\section{Study 4: State of the Union Addresses}

The President of the United States holds the most influential political office in the country and plays a major role in guiding its macro-level social, economic, and foreign policies. Presidential agendas are potentially well captured by State of the Union addresses - i.e., highprofile annual addresses in which the recent and future directions of the country are charted (Maisel, 2007). An additional benefit to analyzing State of the Union addresses is that they have been carefully archived throughout American history. Because this is true, interactive findings concerning such speeches cannot be viewed in terms of recent events, such as the 9/11 terrorist bombings, or cohort effects. We hypothesized an interaction parallel to Study 3, but stronger. 
Individual speeches were analyzed both for pragmatic reasons (i.e., necessary power) and because each speech is its own entity in terms of year-to-year variations in the actual State of the Union and associated changes in the administration's agenda (Winter, 2003).

Method

\section{Text Samples}

Peters' (1999) website archives all available State of the Union addresses, from George Washington's first address to the present, and this Internet resource was used in Study 4. Prior to Ulysses S. Grant, the two-party system did not exist in America as it does today. George Washington did not have a party affiliation, John Adams was a "Federalist", James Madison was a member of the "Democratic-Republican party", and Millard Fillmore was a member of the "Whig" party. Starting with Grant, all presidents have belonged to either the Democratic or Republican party. We therefore downloaded State of the Union texts beginning with Grant's first address. There were a total of 145 addresses, 59 delivered by Democratic presidents and 86 delivered by Republican presidents. The average word count for these speeches was 8560 . Quantifying the Frequency of Affiliation versus Power Words

We used the Harvard IV versions (Stone, 1997) of the General Inquirer dictionaries (Stone et al., 1966) to quantify the frequency of affiliation versus power words in State of the Union addresses, as imported into the LIWC software program (Pennebaker et al., 2007). Power words $(M=5.34 \% ; S D=0.55 \%$; skew $=0.05)$ were more frequent than affiliation words $(M=$ $3.78 \% ; S D=1.39 \%$; skew $=0.08), F(1,143)=58.80, p<.001$, almost certainly due to the different number of words coded per category (Newman et al., 2003). To facilitate within-text comparisons, the word categories were z-scored (Martindale, 1990). 
A mixed-model ANOVA analyzed standardized category frequencies as a function of political ideology and motive theme. There was no main effect for Political Ideology in this analysis, $F(1,143)=1.10, p=.30, \eta_{\mathrm{p}}^{2}=.02$. Thus, interpersonal themes per se do not vary as a function of presidential party. There was also no main effect for Motive Type, $F<1$.

Of more importance, there was a Political Ideology by Motive Type interaction, $F$ (1, $143)=13.90, p<.001, \eta_{\mathrm{p}}{ }^{2}=.09(95 \% \mathrm{CI}: .020-.184)$, the means for which are graphed in Figure 4. Follow-up ANOVAs were performed by party. Democratic State of the Union addresses were marked by a higher frequency of standardized affiliation than power words, $F$ (1, $58)=7.20, p=.001, \eta_{\mathrm{p}}{ }^{2}=.11(95 \% \mathrm{CI}: .007-.268)$. By contrast, Republican State of the Union addresses were marked by a higher frequency of power than affiliation words, $F(1,85)=6.28, p$ $=.01, \eta_{\mathrm{p}}{ }^{2}=.07(95 \% \mathrm{CI}: .003-.188)$. These results conceptually replicate Studies $1-3$ in the context of presidential State of the Union addresses.

\section{Discussion}

The President of the United States has an extraordinary influence on the American political system (Winter, 2003) and it therefore seemed useful to analyze key speeches with respect to the power/affiliation distinction. As predicted, affiliation themes were more prevalent in Democratic State of the Union addresses, post-standardization, and power themes were more prevalent in Republican addresses. The crossover nature of the pattern was stronger than in Study 3, a result that was expected given the ideologically infused nature of presidential politics relative to the greater centrism of American governors (Maisel, 2007).

\section{General Discussion}

We hypothesized that the power versus affiliation contrast would systematically vary by political ideology. Robust support for this idea was found in analyses of the use of power and 
affiliation words in political discourse. Texts posted to liberal chat rooms used more affiliation than power words, post-standardization, whereas the reverse was found for texts posted to conservative chat rooms (Study 1). Similar interactions were observed for pieces contributed to liberal versus conservative news websites (Study 2), State of the State addresses (Study 3), and State of the Union addresses (Study 4). Although follow-up comparisons were not always significant, the hypothesized interaction was always significant and its pattern was largely parallel across datasets. The General Discussion focuses on questions of method and implications for understanding the motivation-related basis of political ideology. In addition, some future directions of research are outlined. An Objective Method of Scoring Affiliation and Power in Texts

Affiliation and power are thought to be implicit in nature. What this means, concretely, is that self-reports of affiliation and power strivings may be suspect (McClelland et al., 1989; Schultheiss, 2013). Rather, it appears more useful to document these themes in written or spoken texts because doing so captures the person's natural train of thinking in relation to these interpersonal concerns (McClelland, 1987).

Implicit affiliation and power are most frequently assessed using TAT-based methodologies, which present pictures and ask individuals to write imaginative stories about them (Schultheiss, 2008). There are limitations to the TAT method, however. One important one is the subjectivity of TAT scoring: Human coders are involved, phrases or sentences rather than words are coded, and inter-rater agreement is less than perfect (McClelland et al., 1989). It would be desirable, if possible, to also develop objective scoring systems.

The LIWC software program removes subjectivity from scoring linguistic texts because it simply counts the frequency of words matching a pre-defined dictionary (Pennebaker et al., 
2007). For example, negative emotionality can be quantified in terms of the frequency with which negative emotion words are used (Rude, Gortner, \& Pennebaker, 2004). Moreover, the LIWC program is very flexible in that it is not dependent on presenting particular pictures, but rather seems to work well with a variety of text sources (Tausczik \& Pennebaker, 2010).

On the other hand, the LIWC does not have dictionaries squarely targeting the power and affiliation categories (Schultheiss, 2013). An important advance in the present studies was therefore that we were able to add these dictionaries to the LIWC on the basis of the extensive thematic work of Stone and colleagues in the 1960s and 1970s (Kelly \& Stone, 1975; Smith, 1968; Stone et al., 1966). Of particular note, these dictionaries were based on the TAT literature (Atkinson, 1958; McClelland, 1961) and they display good levels of agreement with TAT-based human coders (Smith, 1968; Stone et al., 1966). The resulting system is capable of quantifying power and affiliation themes in an objective rather than subjective manner.

There are two limitations of the dictionaries that should be mentioned, though. They code for the occurrence of power and affiliation words in a manner that ignores sentence context. Although one might want to consider context, doing so should be avoided because trying to discern intent from context would compromise the objectivity of the scoring (Tausczik \& Pennebaker, 2010). Turning to a different point, the Harvard IV motive dictionaries were validated by correlating word use with TAT scores rather than by motive induction (Stone et al., 1966). As a result, we do not know for certain whether, for example, power word frequencies would increase if people were placed in a power-arousal condition. We are inclined to think so (Schultheiss, 2013), but further work on this question would be valuable. In the meantime, one could think of the present word frequencies in terms of accessible motivational themes (Eitam \& Higgins, 2010) rather than implicit motives in all documented senses of the phrase. 
As a final note, many LIWC categories stand by themselves - e.g., the frequency of words referring to sports. However, other categories are natural contrasts of each other, such as positive versus negative affect words. For certain purposes, at least, it makes sense to contrast word categories in repeated measures ANOVAs, as we did. In doing so, z-scoring each word category can be advocated in mitigating an unequal number of words per category, thereby better focusing the analysis on repeated measures comparisons. Such procedures were certainly useful in the present context and the findings reinforce others (e.g., Hogenraad, 2005; Winter, 1987) in underlining the utility of the power versus affiliation comparison.

\section{Understanding the Motivational Basis of Political Ideology}

Is there a motivational core to political ideology, as was put forth by psychoanalytic theorists such as Jaensch (1938)? Some commentators have suggested not and, in truth, there is a degree of inconsistency apparent in people's specific political attitudes (Converse, 2000;

McGuire, 1999). Increasingly so, however, the political psychology literature has found reliable self-reported correlates of political ideology that intimate distinct motivational roots. For example, conservatives score higher on self-report measures designed to assess Right Wing Authoritarianism (Altemeyer, 1981), Social Dominance Orientation (Pratto et al., 1994), and intolerance of uncertainty (Jost et al., 2003). Conversely, political liberals often score higher in the trait of openness to experience (Carney et al., 2008).

Many of the self-reported correlates of political ideology are interpreted in motivational terms, yet there is a long line of research suggesting that self-reports are problematic in this realm (McClelland, 1987). Similarly, Jost (2006) has advocated the use of implicit methods in understanding the basis of political ideology and we sought to heed this call. We did so by using text-analysis methods of naturally occurring writing and speech, which are particularly useful in 
capturing spontaneous forms of wanting, thinking, and feeling (Pennebaker et al., 2003) that, in turn, seem likely to manifest themselves in long-term outcomes (McClelland, 1987).

Irrespective of method considerations, no previous studies that we know of had directly contrasted power and affiliation in understanding political ideology. Therefore, the systematic interactions that we observed represent a key contribution to the political psychology literature. The liberal mindset appears to be affiliation-oriented to a greater extent, whereas the conservative mindset appears to be power-oriented to a greater extent. These results, although novel, seem intuitive in capturing a fundamental difference by political ideology.

For example, the policies more greatly favored by liberals include social welfare programs and affirmative action (Kerlinger, 1984), both of which appear affiliation-oriented from a broader perspective (Federico, Weber, Ergun, \& Hunt, 2013). By contrast, the policies more greatly favored by conservatives include increased defense spending and the death penalty (Kerlinger, 1984), both of which are consistent with a desire to be powerful (Kosterman \& Feshbach, 1989). Indeed, conservatives are often more invested in the trappings of power such as wealth and status (Caprara et al., 2006). In sum, the present analysis seems generative in understanding key differences between liberal and conservative people.

Even so, further directions of research can be advocated. First, it would be useful to show that the relative frequency of affiliation versus power words in written texts predicts individual differences in political ideology. Second, it would be useful to show that this relative frequency, as an individual difference variable, predicts the values, moral concerns, attitudes, and traits previously shown to vary by political ideology. Third, it would be useful to show that the relative use of affiliation and power words mediates - and therefore explains - relations between political ideology or party affiliation and its correlates. Finally, we suggest that texts loaded with 
affiliation versus power words might shift political ideology in a corresponding direction, a type of research that would extend the causal implications of the findings.

\section{Conclusions}

On the basis of prior investigations, but extending them, four studies showed that affiliation words were more frequent than power words in liberal texts, whereas the opposite was true of conservative texts, at least in standardized interactive terms. The fundamental distinction between affiliation and power therefore provides a basis for understanding variations in political ideology. We emphasize the assessment method developed as well as the implications of the findings for thinking about motivation-related factors in political orientation. 


\section{References}

Altemeyer, R. A. (1981). Right-wing authoritarianism. Winnipeg, Canada: University of Manitoba Press.

Atkinson, J. W. (1958). Motives in fantasy, action, and society. Princeton, NJ: Van Nostrand.

Barker, D. C. (2002). Rushed to judgment. New York: Columbia University Press.

Barnea, M., \& Schwartz, S. H. (1998). Values and voting. Political Psychology, 19, 17-40.

Caprara, G., Schwartz, S., Capanna, C., Vecchione, M., \& Barbaranelli, C. (2006). Personality and politics: Values, traits, and political choice. Political Psychology, 27, 1-28.

Carney, D., Jost, J. T., Gosling, S. D., \& Potter, J. (2008). The secret lives of liberals and conservatives: Personality profiles, interaction styles, and the things they leave behind. Political Psychology, 29, 807-840.

Converse, P. E. (1964). The nature of belief systems in mass publics. In: D. E. Apter (Ed.), Ideology and discontent (pp. 206-261). New York: Free Press.

Converse, P. E. (2000). Assessing the capacity of mass electorates. Annual Review of Political Science, 3, 331-353.

Crews, F. (2006). Follies of the wise: Dissenting essays. Emeryville, CA: Shoemaker \& Hoard.

Eitam, B., \& Higgins, E. T. (2010). Motivation in mental accessibility: Relevance of a representation (ROAR) as a new framework. Social and Personality Psychology Compass, 4, 951-967.

Federico, C. M., Weber, C. R., Ergun, D., \& Hunt, C. (2013). Mapping the connections between politics and morality: The multiple sociopolitical orientations involved in moral intuition. Political Psychology, 34, 589-610. 
Fetterman, A. K., Robinson, M. D., \& Ode, S. (2015). Interpersonal arrogance and the incentive salience of power versus affiliation cues. European Journal of Personality, 29, 28-41.

Fromm. E. (1947). Man for himself: An inquiry into the psychology of ethics. New York: Holt, Rinehart, and Winston.

Gosling, S. D., Sandy, C. J., John, O. P., \& Potter, J. (2010). Wired but not WEIRD: The promise of the Internet in reaching more diverse samples. Behavioral and Brain Sciences, $33,94-95$.

Graham, J., Haidt, J., \& Nosek, B. A. (2009). Liberals and conservatives rely on different sets of moral foundations. Journal of Personality and Social Psychology, 96, 1029-1046.

Hogenraad, R. (2003). The words that predict the outbreak of wars. Empirical Studies of the Arts, $21,5-20$.

Hogenraad, R. (2005). What the words of war can tell us about the risk of war. Peace and Conflict: Journal of Peace Psychology, 11, 137-151.

Jaensch, E. R. (1938). Der Gegentypus. Leipzig, Germany: J.A. Barth.

Jost, J. T. (2006). The end of the end of ideology. American Psychologist, 61, 651-670.

Jost, J. T., Glaser, J., Kruglanski, A. W., \& Sulloway, F. (2003). Political conservatism as motivated social cognition. Psychological Bulletin, 129, 339-375.

Kelly, E. F., \& Stone, P. J. (1975). Computer recognition of English word senses. Amsterdam, Netherlands: North Holland.

Kerlinger, F. N. (1984). Liberalism and conservatism: The nature and structure of social attitudes. Hillsdale, NJ: Erlbaum.

Kihlstrom, J. F. (1987). The cognitive unconscious. Science, 237, 1445-1452. 
Kosterman, R., \& Feshbach, S. (1989). Towards a measure of patriotic and nationalistic attitudes. Political Psychology, 10, 257-274.

Lakoff, G. (1996). Moral politics. Chicago: University of Chicago Press.

Litwin, G. H. (1965). The language of achievement: An analysis of achievement related themes in fantasy using mechanical methods. Unpublished doctoral dissertation.

Maisel, S. (2007). American political parties and elections. New York: Oxford University Press.

Martindale, C. (1990). The clockwork muse: The predictability of artistic change. New York: Basic Books.

McClelland, D. C. (1961). The achieving society. New York: Van Nostrand.

McClelland, D. C. (1975). Power: The inner experience. New York: Irvington Publishers.

McClelland, D. C. (1987). Human motivation. New York: Cambridge University Press.

McClelland, D. C., Koestner, R., \& Weinberger, J. (1989). How do self-attributed and implicit motives differ? Psychological Review, 96, 690-702.

McGuire, W. J. (1999). The vicissitudes of attitudes in social psychology. In: W. J. McGuire (Ed.), Constructing social psychology: Creative and critical processes (pp. 325-347). Cambridge, England: Cambridge University Press.

Mehl, M. R. (2006). Quantitative text analysis. In: M. Eid \& E. Diener (Eds.), Handbook of multimethod measurements in psychology (pp. 141-156). Washington, DC: American Psychological Association.

Newman, M. L., Groom, C. J., Handelman, L. D., \& Pennebaker, J. W. (2008). Gender differences in language use: An analysis of 14,000 text samples. Discourse Processes, 45, 211-236. 
Newman, M. L., Pennebaker, J. W., Berry, D. S., \& Richards, J. M. (2003). Lying words: Predicting deception from linguistic styles. Personality and Social Psychology Bulletin, 29, 665-675.

Pennebaker, J. W., Chung, C. K., Ireland, M., Gonzales, A. L., \& Booth, R. J. (2007). The development and psychometric properties of LIWC2007. Austin, TX: www.LIWC.net

Pennebaker, J. W., \& King, L. A. (1999). Linguistic styles: Language use as an individual difference. Journal of Personality and Social Psychology, 77, 1296-1312.

Pennebaker, J. W., Mehl, M. R., \& Niederhoffer, K. G. (2003). Psychological aspects of natural language use: Our words, our selves. Annual Review of Psychology, 54, 547-577.

Peters, G. (1999). State of the Union addresses and messages. In American Presidency Project. Retrieved June 2010. http://www.presidency.ucsb.edu.

Piurko, Y., Schwartz, S. H., \& Davidov, E. (2011). Basic personal values and the meaning of left-right political orientations in 20 countries. Political Psychology, 32, 537-561.

Pratto, F., Sidanius, J., Stallworth, L. M., \& Malle, B. F. (1994). Social Dominance Orientation: A personality variable predicting social and political attitudes. Journal of Personality and Social Psychology, 67, 741-763.

Rude, S. S., Gortner, E., \& Pennebaker, J. W. (2004). Language use of depressed and depressionvulnerable college students. Cognition and Emotion, 18, 1121-1133.

Schultheiss, O. C. (2008). Implicit motives, In: O. P. John, R. W. Robins, \& , L. A. Pervin (Eds.) Handbook of personality psychology: Theory and research (3rd ed.). New York: Guilford Press. 
Power versus Affiliation 33

Schultheiss, O. C. (2013). Are implicit motives revealed in mere words? Testing the markerword hypothesis with computer-based text analysis. Frontiers in Psychology, 4, doi: 10.3389/fpsyg.2013.00748.

Shils, E. A. (1968). The end of ideology? In: C. Waxman (Ed.), The end of ideology debate (pp. 49-63). New York: Simon \& Schuster.

Sidanius, J., \& Pratto, F. (1999). Social dominance. New York: Cambridge University Press.

Slatcher, R. B., Chung, C. K., Pennebaker, J. W., \& Stone, L. D. (2007). Winning words: Individual differences in linguistic style among U.S. presidential and vice presidential candidates. Journal of Research in Personality, 41, 63-75.

Smith, M. S. (1968). The computer and the TAT. Journal of School Psychology, 6, 206-214.

Stone, P. J. (1997). Thematic text analysis: New agendas for analyzing text content. In: C. W. Roberts (Ed.), Text analysis for the social sciences: Methods for drawing statistical inferences from texts and transcripts (pp. 35-54). Mahwah, NJ: Erlbaum.

Stone, P. J., Dunphy, D. C., Smith, M. S., \& Ogilvie, D. M. (1966). The General Inquirer: A computer approach to content analysis. Cambridge, MA: MIT Press.

Tausczik, Y. R., \& Pennebaker, J. W. (2010). The psychological meaning of words: LIWC and computerized text analysis methods. Journal of Language and Social Psychology, 29, 2454.

Thorisdottir, H., Jost, J. T., \& Kay, A. C. (2009). On the social and psychological bases and system justification. In: J. T. Jost, A. C. Kay, \& H. Thorisdottir (Eds.), Social and psychological bases of ideology and system justification (pp. 3-23). New York: Oxford University Press. 
Trapnell, P. D., \& Paulhus, D. L. (2012). Agentic and communal values: Their scope and measurement. Journal of Personality Assessment, 94, 39-52.

Winter, D. G. (1987). Leader appeal, leader performance, and the motive profiles of leaders and followers: A study of American presidents and elections. Journal of Personality and Social Psychology, 52, 196-202.

Winter, D. G. (1993). Power, affiliation and war: Three tests of a motivational model. Journal of Personality and Social Psychology, 65, 532-545.

Winter, D. G. (2003) Measuring the motives of political actors at a distance. In: J. M. Post (Ed.), The psychological assessment of political actors: With profiles of Saddam Hussein and Bill Clinton (pp. 153-177). Ann Arbor, MI: University of Michigan Press.

Winter, D. G., John, O. P., Stewart, A. J., Klohnen, E. C., \& Duncan, L. E. (1998). Traits and motives: Toward an integration of two traditions in personality research. Psychological Review, 105, 230-250. 
Power versus Affiliation 35

\section{Footnotes}

${ }^{1}$ The chat room context was one in which there was a sizable correlation between the use of power and affiliation words, $r=.55, p<.01$, as some chat room discussions were more "social" than others. These correlations were quite a bit smaller in the remaining studies $(r=.10$, $p=.01$ in Study 2, $r=.16, p=.00$ in Study 3, and $r=.31, p=.00$ in Study 4).

${ }^{2}$ The interactions reported in this paper were robust to different ways of handling the data. Specifically, we performed 2 (Ideology) by 2 (Word Category) ANOVAs on raw word frequency scores, standardized raw frequency scores, log-transformed word frequency scores, and standardized log-transformed word frequency scores. In Study 1, interaction $p$-values ranged from 0 to .002 and interaction effect sizes $\left(\eta_{\mathrm{p}}{ }^{2}\right)$ ranged from .04 to .05. In Study 2, these ranges were 0 to .001 ( $p$-values) and .07 to .10 (effect sizes). In Study 3, both quantities ranged from .01 to .02. In Study 4, finally, interaction $p$-values ranged from 0 to .001 and effect size estimates varied from .09 to .10. Thus, interactive conclusions would be the same regardless of analysis. 
Figure 1

Motivation-Related Word Frequencies by Chat Room Ideology, Study 1

Figure 2

Motivation-Related Word Frequencies by Website Ideology, Study 2

Figure 3

Motivation-Related Word Frequencies by Governor Ideology, Study 3

Figure 4

Motivation-Related Word Frequencies by President Ideology, Study 4 
Power versus Affiliation 37

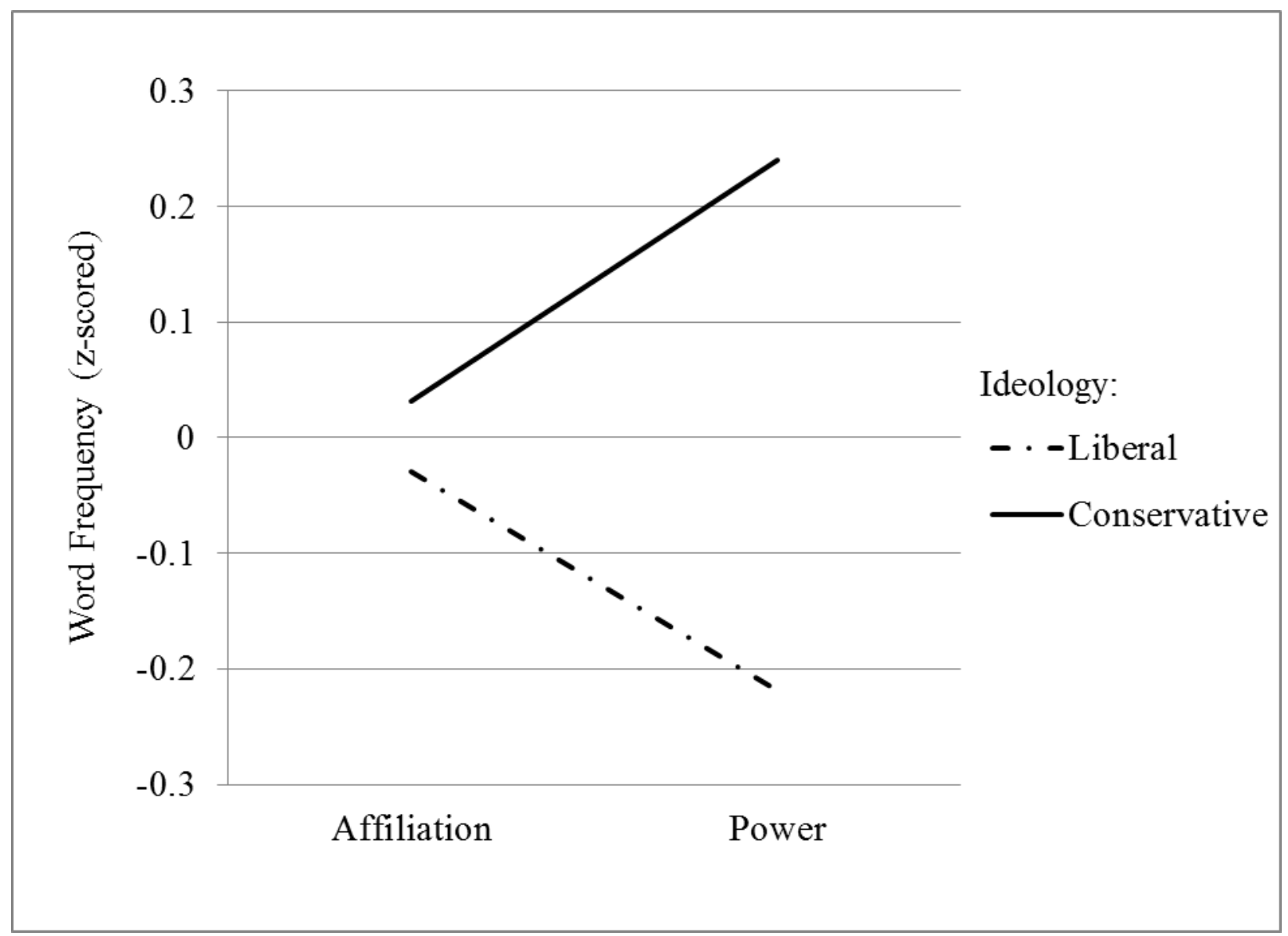


Power versus Affiliation 38

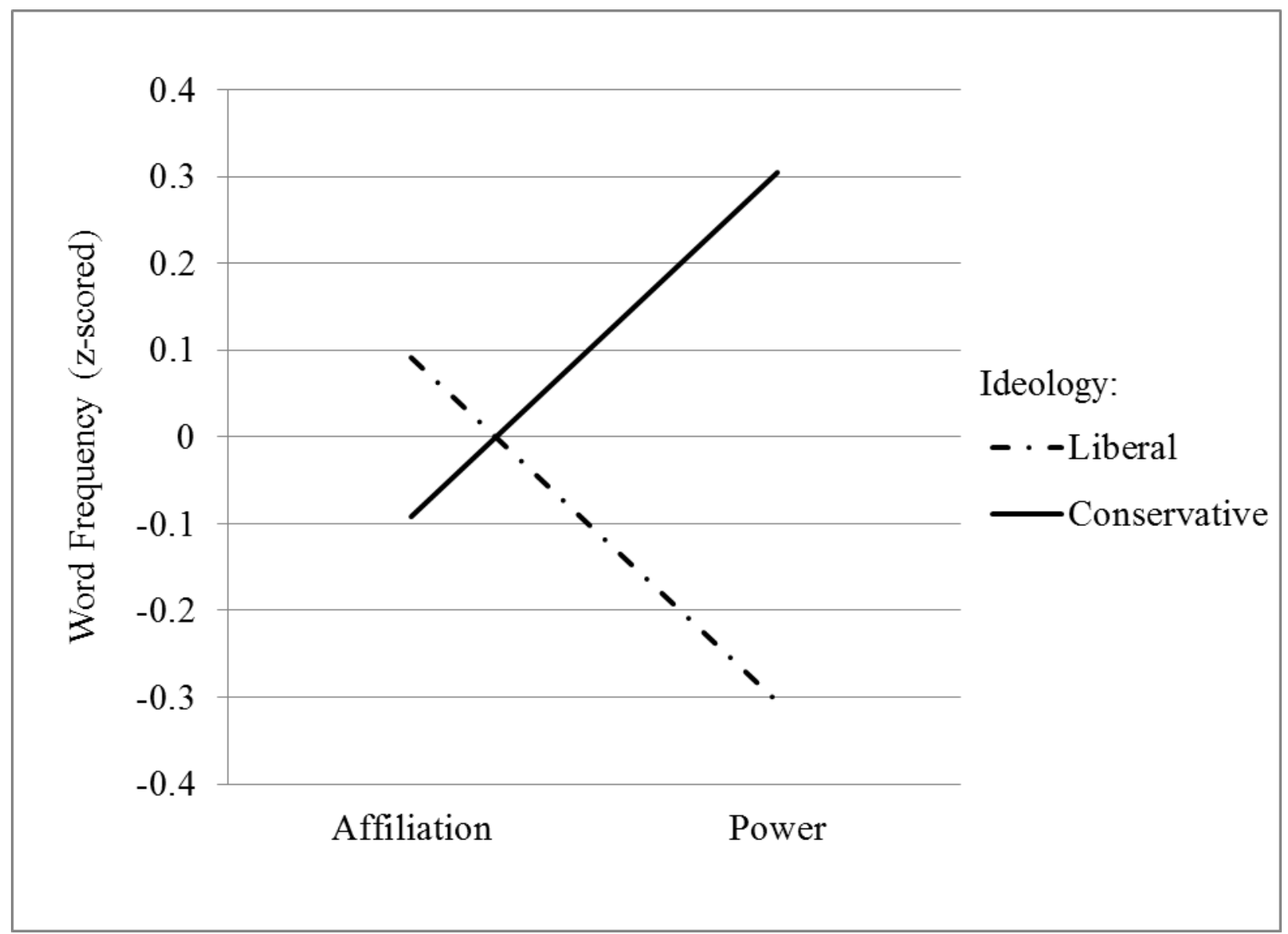


Power versus Affiliation 39

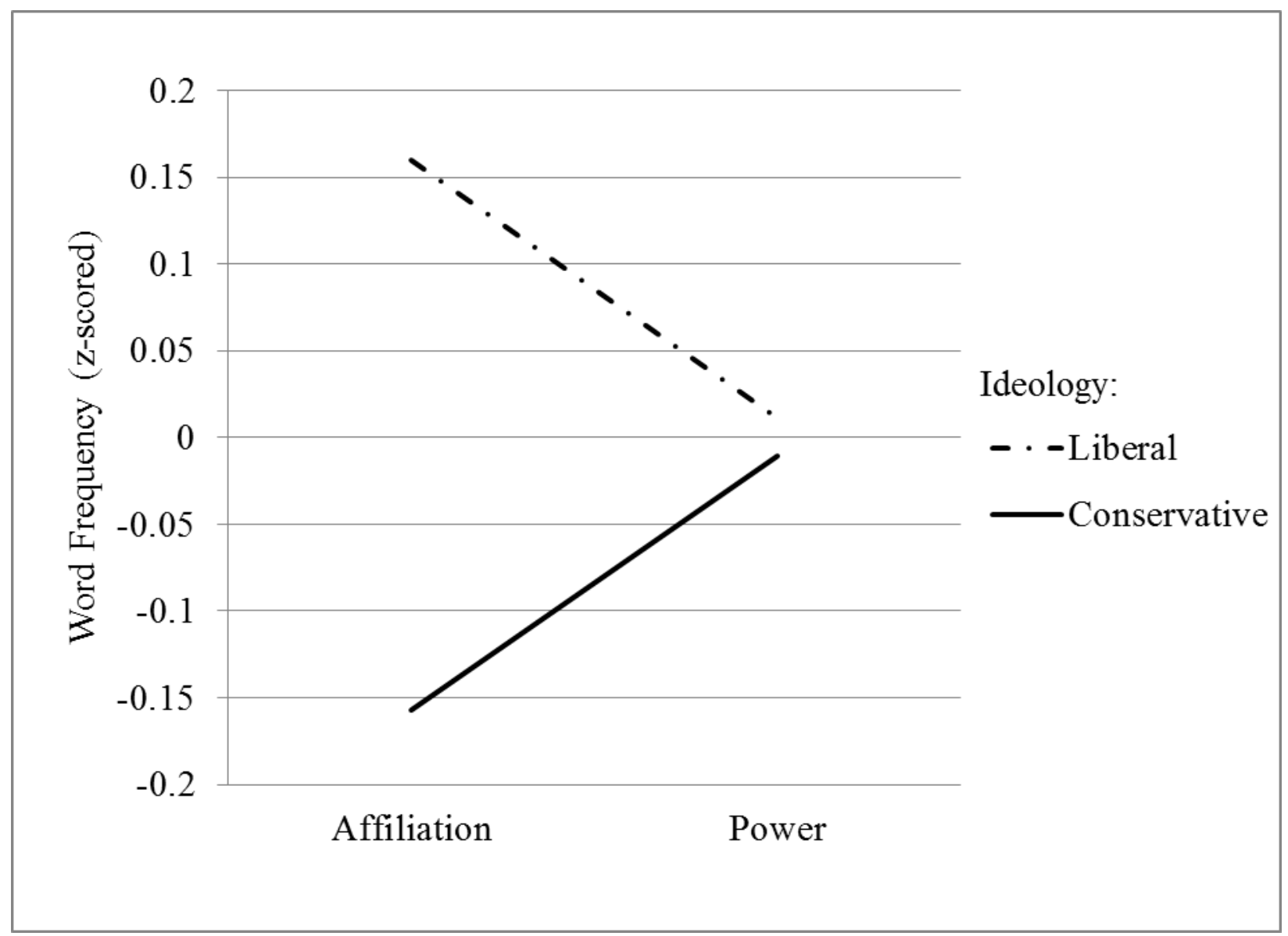


Power versus Affiliation 40

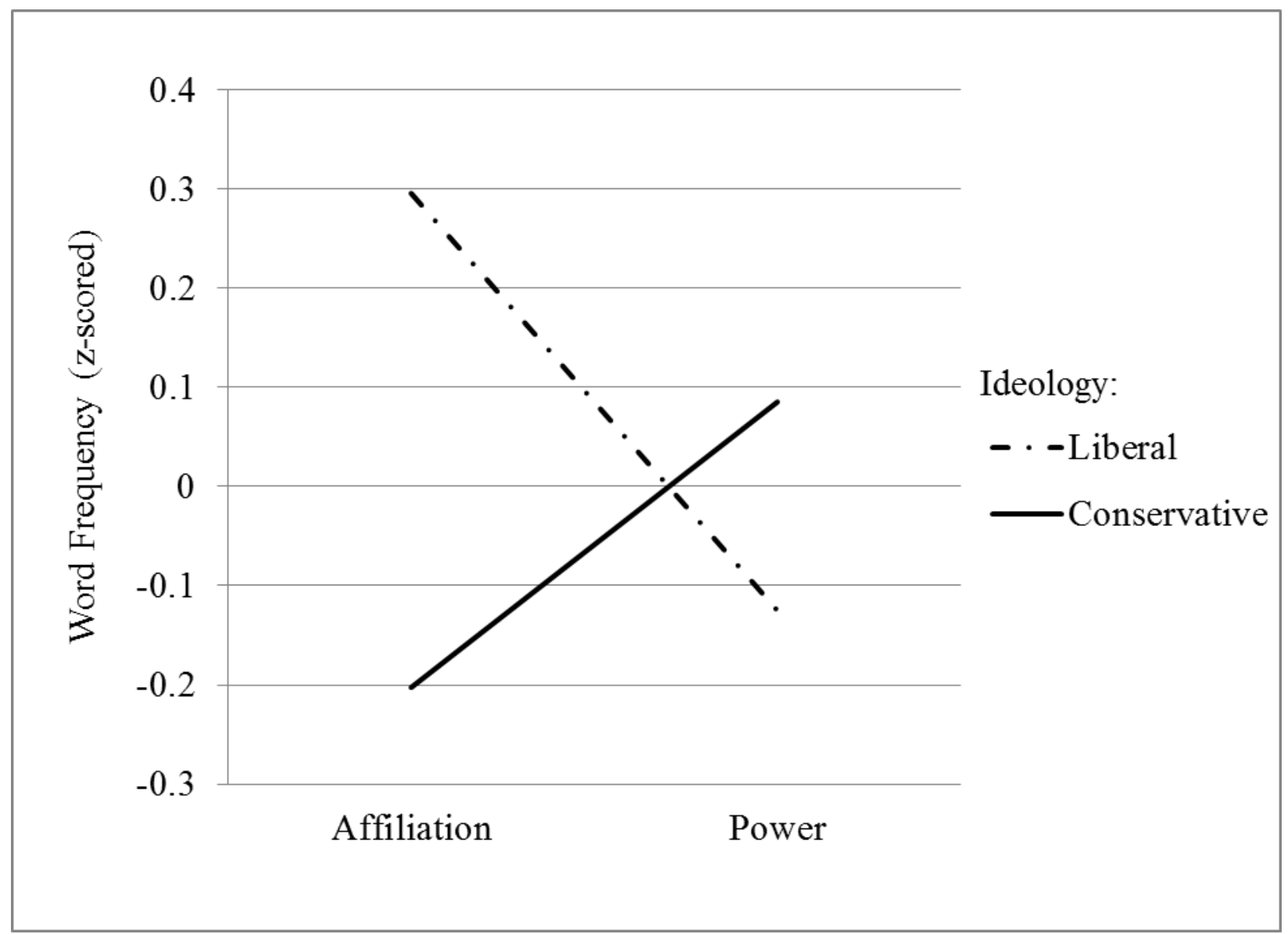

